Polymer Journal Vol. 6, No. 1, pp 79-81 (1974)

SHORT COMMUNICATION

\title{
Electrical Conduction in Glass Transition Region of Polymer
}

\author{
Teruo Miyamoto and Kyoichi Shibayama \\ Central Research Laboratory, Mitsubishi Electric Corporation, \\ Amagasaki, Hyogo, Japan.
}

(Received August 31, 1973)

KEY WORDS Electrical Conduction / Glass Transition / Poly-
(methyl methacrylate) / Polystyrene /

The electrical conduction of polymers in relatively low electric fields is considered to be ionic. Evidence for the ionic mechanism can be supplied from Faraday's law observed in a gas evolution experiment under applied voltage ${ }^{1}$ and from the dependence of electrical conductivity on pressure, ${ }^{2}$ free volume, ${ }^{3}$ and degree of crystallinity. ${ }^{4}$

In ionic conduction the slope in the logarithmic electrical conductivity $v s$. reciprocal absolute temperature plots changes at a critical temperature. The critical temperature coincides approximately with the glass transition temperature, as observed by many authors. ${ }^{5-7}$ However, strictly speaking, the critical temperature does not always coincide with the glass transition temperature and is, usually, observed to be lower than the glass transition temperature.

The purpose of this study is to elucidate the relation between the critical temperature and the glass transition temperature.

The poly(methyl methacrylate) (PMMA) and polystyrene (PS) used in the measurements were prepared by polymerization of the distilled monomer, using $\alpha, \alpha^{\prime}$-azobisisobutyronitrile and benzoil peroxide as initiators for the former and the latter respectively. Specimens were polymerized by heating at about $90^{\circ} \mathrm{C}$ for $4 \mathrm{hr}$, then at $120^{\circ} \mathrm{C}$ for $4 \mathrm{hr}$ between two glass plates, and finally at $160^{\circ} \mathrm{C}$ for $14 \mathrm{hr}$ in a vacuum.

The electrical conductivity was measured by a Vibrating Reed Electrometer (Takeda Riken Co., TR-84M). The temperature was varied at a cooling rate of $1^{\circ} \mathrm{C} / \mathrm{min}$, obtained with a programmed temperature controller after a steadyleakage electric current was attained at $160^{\circ} \mathrm{C}$ in order to avoid any influence of the absorp- tion electric current.

Dielectric properties were measured over the frequency range from $30 \mathrm{~Hz}$ to $100 \mathrm{kHz}$ and the temperature range from room temperature to $200^{\circ} \mathrm{C}$ by a mutual inductance bridge (Ando Electric Co., TR-10C).

The dependence of specific volume on temperature is shown in Figure 1. The intersection of the oblique lines shows the glass transition temperature. The glass transition temperature can usually be identified as the onset of diffusional motion of the main polymer chain. At temperatures below the glass transition temperature the motion is hindered by potential energy barriers. With increasing temperature the energy becomes great enough to overcome this barrier and the segmental motion occurs. The greater mobility of the polymer segments, at the same time, results from an increase in the free volume of the system. This behavior and the dependence of electrical conductivity on temperature correlate closely with each other. Arrhenius plots of electrical conduction are shown in Figure 2. A marked increase in electrical conductivity at temperatures above the glass transition temperature, therefore, is considered to favour the ionic conduction mechanism in these polymers. Both the mobility of the ionic charge carriers and the diffusional mobility of the chain segment closely correlate with each other, and are considered to be regulated mainly by the size of the hole required for transport. This hole formation would be dependent on the amount and distribution of the free volume. The free volume in polymers increases with temperature above the glass transition temperature $T_{\mathrm{g}}$ and is approximately constant at temperature below 
$T_{\mathrm{g}}{ }^{8} \quad$ A hole is created by opposing internal and external pressure at temperatures above the critical temperature $T_{\mathrm{i}}$ and $T_{\mathrm{g}}$, respectively. The relation is expressed by thermodynamic considerations as follows:

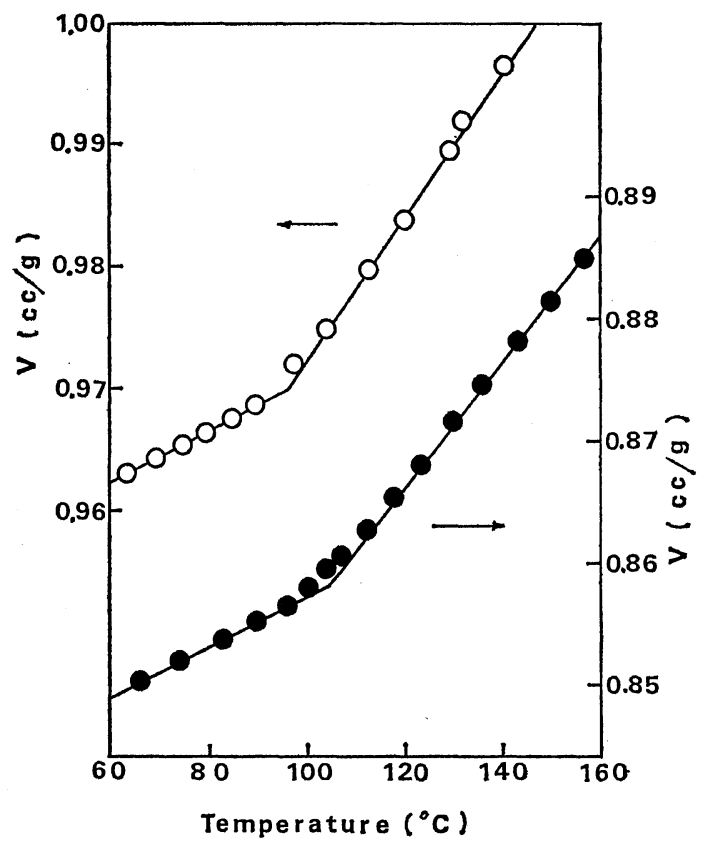

Figure 1. Specific volume $(V)$ vs. temperature: ○, poly(methyl methacrylate); $\bigcirc$, polystyrene.

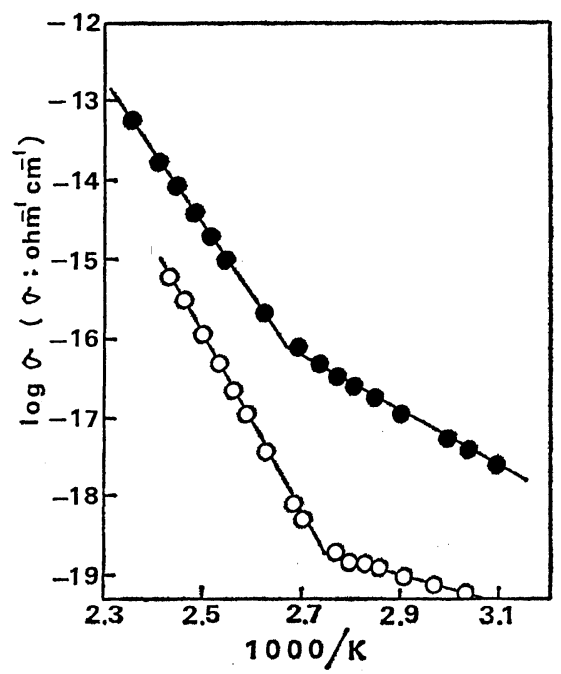

Figure 2. Electrical conductivity $(\sigma) v s$. reciprocal temperature: - poly(methyl methacrylate); $O$, Polystyrene.

$$
\frac{\left(P_{\mathrm{i}}+P\right) V_{\mathrm{i}}^{*}}{T_{\mathrm{i}}-T_{\mathrm{g} 1}}=\frac{\left(P_{\mathrm{g}}+P\right) V_{\mathrm{s}}^{*}}{T_{\mathrm{g}}-T_{\mathrm{g} 1}}
$$

where $P_{\mathrm{i}}$ is the internal pressure at $T_{\mathrm{i}}, P$ is the external pressure, and $V_{i}^{*}$ is the critical hole size required for transport of the ionic charge carrier. $T_{\mathrm{g} 1}$ is the lowest attainable limit of $T_{\mathrm{g}}, P_{\mathrm{g}}$ is the internal pressure at $T_{\mathrm{g}}$, and $V_{\mathrm{s}}^{*}$ is the critical hole size required for segmental motion. If the difference between $P_{\mathrm{i}}$ and $\boldsymbol{P}_{\mathrm{g}}$ is assumed to be very small, $T_{\mathrm{i}}$ is expressed by the form

$$
T_{\mathrm{i}} \fallingdotseq \frac{V_{\mathrm{i}}^{*}}{V_{\mathrm{s}}^{*}}\left(T_{\mathrm{g}}-T_{\mathrm{g} 1}\right)+T_{\mathrm{g} 1}
$$

The fac that $T_{1}$ does not always coincide with $T_{\mathrm{g}}$ is asidered to be mainly due to a difference in the size of $V_{\mathrm{i}}^{*}$ and $V_{\mathrm{s}}^{*}$, as easily presumed. As can be seen from eq 2 , if the main source of the charge carriers were the impurities existing in the polymer, $T_{\mathrm{i}}$ would change for different species of impurity. On the other hand, the ratio of $V_{\mathrm{i}}^{*}$ to $V_{\mathrm{s}}^{*}$ is expressed as follows: ${ }^{9}$

$$
\frac{V_{\mathrm{i}}^{*}}{V_{\mathrm{s}}^{*}}=\frac{E_{\mathrm{a}}-E_{\mathrm{b}}}{E_{\mathrm{s}}}
$$

where $E_{\mathrm{a}}$ and $E_{\mathrm{b}}$ are the apparent activation energy for the electrical conduction process at temperatures above and below $T_{\mathrm{i}}$, respectively, and $E_{\mathrm{s}}$ is the apparent activation energy for segmental motion obtained from the temperature dependence of the dielectric relaxation time. Values of $T_{\mathrm{g}}, T_{\mathrm{i}}$, and the activation energy are listed in Table I. The values of $V_{\mathrm{i}}^{*} / V_{\mathrm{s}}^{*}$ are 0.27 and 0.48 for PMMA and PS respectively. Experimental determination of $T_{\mathrm{g} 1}$ is difficult; $T_{\mathrm{g} 1}$ was assumed here to be close to the lower limit of the glass transition region. The value of $T_{1}$ calculated from eq 2 is listed in Table I, together with other characteristic values. If the result that the temperature range between $T_{\mathrm{g}}$ and $T_{\mathrm{g} 1}$ is about 10 degrees is taken into consideration, the calculated $T_{\mathrm{i}}$ well coincides with the observed $T_{\mathrm{i}}$.

Since knowledge of the nature of electrical conduction is incomplete, it is sometimes not clear whether the charge transfer process involves the transport of ions or electrons for a certain polymer. The transport phenomena of the charge carrier at the glass transition region discussed here could be regarded as an additional 
Electrical Conduction in Glass Transition Region of Polymer

Table I. Characteristic values for $T_{\mathrm{i}}$ calculation in polymers

\begin{tabular}{lrrrrrrrr}
\hline \multirow{2}{*}{ Sample } & $T_{\mathrm{g}}$, & $T_{\mathrm{i}}$, & $T_{\mathrm{g} 1}$, & & $E_{\mathrm{a}}$, & $E_{\mathrm{b}}$, & $E_{\mathrm{s}}$, & \multirow{2}{*}{$T_{\mathrm{i}}$ (calcd), } \\
\cline { 2 - 4 } \cline { 7 - 8 } & \multicolumn{3}{c}{${ }^{\circ} \mathrm{C}$} & \multicolumn{3}{c}{$\mathrm{kcal} / \mathrm{mol}$} \\
\hline Poly(methyl methacrylate) & 105 & 100 & 95 & & 42.8 & 14.7 & 102.9 & 98 \\
Polystyrene & 97 & 91 & 83 & & 50.9 & 7.4 & 90.1 & 90 \\
\hline
\end{tabular}

source of information about the nature of the charge carrier.

\section{REFERENCES}

1. E. S. Murphy, Canad. J. Phys., 41, 1022 (1963).

2. S. Saito, H. Sasabe, T. Nakajima, and fo Yada, J. Polym. Sci., Part A-2, 6, 1297 (1968).

3. T. Miyamoto and K. Shibayama, Kobunshi Kagaku (Chem. High Polymers), 29, 301 (1972).

4. B. I. Zazhin and N. G. Podesenova, Sov. Phys. Solide State, 6, 1755 (1965).
5. R. E. Barker and C. R. Thomas, J. Appl. Phys., 35, 3203 (1964).

6. R.W. Warfield and M.C. Petree, Makromol. Chem., 58, 139 (1962).

7. D. D. Eley and D. I. Spivey, Trans. Faraday Soc., 57, 2280 (1961).

8. M. Boyer, Rubber Chem. Technol., 36, 1303 (1963).

9. T. Miyamoto and K. Shibayama, Kobunshi Kagaku (Chem. High Polymers), 30, 103 (1973). 